\title{
Annexin A1 is responsible for ursolic acid mediated anticancer effects on breast cancer stem cells by wnt/ $\beta$-catenin pathway
}

shujun fan ( $\sim 1472870300 @ q q . c o m$ )

Dalian Medical University

Ruixue Xu

The First Affiliated Hospital of dalian medical university

Han Zhang

Dalian Medical University

Jun Mao

Dalian Medical University

Qingqing Zhang

Dalian Medical University

Ying Lu

Dalian Medical University

Mei Wang

Dalian Medical University

Huaxin Wang

Dalian medical universiy

Xiaotang Yu

Dalian Medical University

Zhenhuan Hou

Dalian Medical University

Xu Sun

First Affiliated Hospital of Dalian Medical University

Yuanyi Wei

Dalian medical university

Yuhong Huang

Dalian Medical University

Bo Wang

Dalian Medical University

\section{Bo Song}

Dalian Medical University

Lianhong Li 


\section{Research}

Keywords: AnxA1, ursolic acid, breast cancer stem cell, epithelial mesenchymal transformation, wnt / $\beta$ catenin

Posted Date: December 18th, 2020

DOI: https://doi.org/10.21203/rs.3.rs-130214/v1

License: (c) (1) This work is licensed under a Creative Commons Attribution 4.0 International License. Read Full License 


\section{Abstract \\ Background}

Ursolic acid (UA), a plant extract from traditional Chinese medicines as well as edible vegetables, exhibits a potent anticancer activity in various tumor cells. Annexin A1(AnxA1) is dysregulated and play a pivotal role in various tumor. However, the function of $A n x A 1$ in breast cancer(BC) remains unclear.

\section{Methods}

Western blot, real-time quantitative polymerase chain reaction(qRT- PCR), transwell, wound healing and immunofluorescence were used to study the biological features of AnxA1 in breast cancer. The stemness of cancer cells was assessed by sphere formation assay. CCK-8 and flow cytometry assay were used to detect the effects of ursolic acid on the growth, proliferation and apoptosis of breast cancer cells in vitro. A nude mice xenograft model was employed in vivo. The potential mechanism by which Ursolic acid regulates the biological behaviors of breast cancer stem cells through AnxA1 via the wnt/ $\beta$-catenin signaling pathway was tested by western blot, qRT- PCR and immunohistochemistry.

\section{Results}

AnxA1 was highly expressed in MDA-MB-231 cell line compared with MCF-7 cell line, Down-regulation of AnxA1 could reduce the mammosphere formation, inhibit EMT, decrease the ability of migration and invasion in MCF-7 and MDA-MB-231 cells. Ursolic acid can reduce the expression of AnxA1 and inhibit proliferation of breast cancer cells, stemness, EMT, migration and invasion, promote cell apoptosis of breast cancer cell. This studies suggest that the anticancer effects of AnxA1 knockdown and UA treatment may be realized by affecting the EMT process and the wnt/ $\beta$-catenin signaling pathway.

\section{Conclusions}

This research suggest that AnxA1 knockdown enhanced the sensitivity of breast cancer cells to UA, the combination of UA treatment and AnxA1 knockdown possesses multiple anti-tumor activities against breast cancer, as it, in particular, inhibited the cancer stem cell and attenuated EMT. Therefore, it is emerging as a promising therapeutic strategy to inhibit breast cancer.

\section{Background}

Breast cancer is the most common cancer and the leading cause of cancer death in female. In 2018, an approximate 2.1 million female were newly confirmed with breast cancer, accounting for about a quarter of cancer cases in women, almost one new case diagnosed every 18 seconds[1-2]. Breast cancer stem cells(BCSCs) are defined as a limited group of breast cancer initiating cells, possessing of self-renewal, 
and differentiation potential, responsible for cancer recurrence, metastasis, treatment resistance and hyperactivation of signaling pathways that control stemness [3]. $\mathrm{CD} 44^{+} / \mathrm{CD} 24^{-/ \text {low }}$ and aldehyde dehydrogenase ${ }^{+}\left(\mathrm{ALDH}^{+}\right)$are the most common markers to identify BCSCs [4-5]. BCSCs have been identified as the "ringleader" for the drug resistance in breast cancer treatment and have been pointed as targets of new therapies for breast cancer [6-7]. Herein,it is urgency to repurpose certain drugs as BCSCtargeting agents.

Ursolic acid(UA,or 3- $\beta$-hydroxy-urs-12-en-28-oic acid), a pentacyclic triterpene acid,is widely distributed in different fruits and vegetables[8].Recently UA has attracted great attention for its comprehensive biological properties,including anti-inflammatory,chemopreventive and anticancer[9-12],Ursolic acid shows strong anticancer effects against breast cancer through targeting multiple signaling pathways[13-14]. Shan et al. [15]reported that UA was able to suppress the proliferation of MCF-7and MCF-7/ADR BC cells with IC50 values of 30 and $40 \mu$ mol respectively. Kim et al. [16] found that UA induced apoptosis of MDA-MB-231 human breast cancer cells through the intrinsic mitochondrial death pathway and the extrinsic death receptor pathway. Shishodia et al. [17]suggested that ursolic acid regulated cytokine signaling pathway by inhibiting TNF-induced NF-KB activation. Although ursolic acid exerts anticancer activity by inhibiting proliferation, metastasis and induced apoptosis in breast cancer[18],the exact mechanism of ursolic acid still remains unclear in breast cancers.

Annexin a1(AnxA1) belongs to a structurally homologous calcium-dependent phospholipid-binding protein superfamily[19].It is mainly distributed in nucleus, cytoplasm and cytomembrane of various cell types. It regulates a variety of biological processes such as cellular transport, phagocytosis, hormone secretion, proliferation, apoptosis and cell differentiation[20-25]. Accumulated evidence has indicated that AnxA1 are involved in the carcinogenesis, invasion, metastasis in many tumor[26-27], and its positive expression is quite discrepant depending on the types of cancer [28], upregulation in pancreatic, hepatic, glial cancers, while downregulation in prostate, esophageal and laryngeal cancer. Nevertheless, the exact function of AnxA1 in breast cancer is still unclear, and the modulation of AnxA1 on BCSCs needs to be clarified.

In this study, we find that AnxA1 is significantly upregulated in MDA-MB-231 cell line,Ursolic acid inhibits proliferation, induces apoptosis and mediates the process of epithelial-mesenchymal transition(EMT) due to uniting AnxA1 knockdown that can reduce the activity of wnt/ $\beta$-catenin pathway and as well as in the subpopulation of BCSCs both in vitro and in vivo. In addition, we also showed that depletion of AnxA1 enhanced the biological effect of ursolic acid, and the suppression of AnxA1 in combination with ursolic acid might efficiently restrain tumor growth as well as metastasis.

\section{Methods}

\section{Cell culture, reagents and animals}


Human breast cancer cell lines(MCF-7 and MDA-MB-231) came from pathological department of Dalian Medical University. Both the two cell lines were maintained in DMEM/F12(1:1)with $10 \%$ FBS at $37^{\circ} \mathrm{C}$ in a incubation box $\left(5 \% \mathrm{CO}_{2}, 95 \%\right.$ air $)$.

UA was acquired from Sigma company.

BALB/c nude mice aging 6 to 8 weeks were abtained from Vital River Laboratory Animal Technology Company (Beijing ,China). Animal care complied with the rules of the Animal Protection and Use Committee of this University.

\section{AnxA1 siRNA transfection}

siRNAs special for AnxA1 was purchased from GenePharma Company (Shanghai, China). The siRNA targeting AnxA1 were as follows: (siA1\#1,5'-CCUUACCACCAGAAGCUAUTT -3' and

5'-AUAGCUUCUGGUGGUAAGGTT -3'; siA1\#2, 5'-GCCAUGAAAGGUGUUGGAATT-3'and 5'-

UUCCAACACCUUUCAUGGCTT-3'). Cells were transfected in 6-well plates(Guangzhou Jet Bio-Filtration Co., Ltd) with Lipofectamine 3000 (Invitrogen) on the base of the product manual.

\section{Stable transfection with lentiviral vectors}

To overexpress AnxA1 in BC cells, the LV3(H1/GFP\&Puro) plasmids from GenePharma Company were infected into MDA-MB-231 cells by Lipofectamine 3000. The sequence of short hairpin RNA (shRNA) against AnxA1 was as follows: 5'-GCCATGAAAGGTGTTGGAA-3'. The expression was detected by fluorescence microscopy, qRT-PCR and western blotting analyses.

\section{Cell viability assay}

The detection of cell viability was evaluated by Cell Counting Kit-8 (CCK-8) assay kit . Breast cells dealt with UA or AnxA1 siRNA were reseeded in 96 -well plates for $0 \mathrm{~h}, 24 \mathrm{~h}, 48 \mathrm{~h}$, which was co-incubated with $10 \mu \mathrm{l}$ of CCK8 solution per well for $2 \mathrm{~h}$. The absorbance at $450 \mathrm{~nm}$ was detected. Blank control was the same medium. All tests were repeated three times.

\section{Spheroid formation assay}

The treated Cells were cultivated with serum-free DMEM/F12 in ultra-low-attachment six-well plates (Jet) (1000 cells/well), replenished by $20 \mathrm{ng} / \mathrm{ml}$ human recombinant EGF, $20 \mathrm{ng} / \mathrm{ml} \mathrm{bFGF,} \mathrm{B27} \mathrm{for} \mathrm{two} \mathrm{weeks.}$ Spheroid colonies were examined under Olympus phase contrast microscope(Japan).

\section{Flow cytometry analysis}

Apoptosis was analysed by flow cytometry with Annexin V-APC/PI Apoptosis Detection Kit (BD, USA).

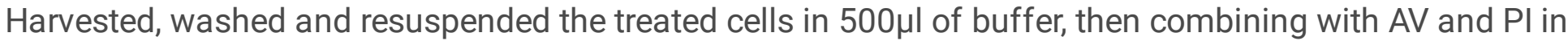


dark place for $15 \mathrm{~min}$. Cells were analyzed by a FACS flow cytometer (BD Biosciences). This experiment was repeated in triplicate.

\section{Invasion assays}

Two hundred microlitres of cell suspension without serum $\left(1 \times 10^{5} \mathrm{cells}\right)$ was seeded into the upper compartment of $8 \mu \mathrm{m}$ pore sized Transwell chamber (Jet) with BD Matrigel (BD Bioscience). Six hundred microlitres of medium supplied with $20 \%$ foetal bovine serum was added into the lower compartment. The cells on the upper chamber passed through the Matrigel and membrane downward. The upper surface of chamber was cleaned with swab, while the lower surface were fixed with $4 \%$ paraformaldehyde and dyed with $0.1 \%$ crystal violet. The number of invading cells was counted and photographed.

\section{Wound healing assay}

When the cells grown in 12-well plates(Jet) were up to $80 \%$ confluence, the monolayer cells were scratched with a 200- $\mu$ l pipette tip. Then the wounded centers were washed with PBS to remove the debris and either sides were in DMEM without FBS for up to 48 hours. The wound closer was detected and was captured by an Olympus phase contrast microscope at $0 \mathrm{~h}, 36 \mathrm{~h}$ and $48 \mathrm{~h}$.

\section{RNA extraction and qRT-PCR}

Total RNA was extracted with Trizol reagent (Transgen) and reversely transcribed into cDNA with the Transgen manual. The mRNA expressions of AnxA1 and $\beta$-catenin were quantified by RT- PCR and analyzed with Transgen mixture kit according to the manufacture's recommendations. This is the sequences: AnxA1, 5'-ACCGATCTGAGGACTTTGGTGTG-3'and 5'-CGAAGTTGTGGATAGCTTCTGGTG-3', $\beta$ catenin, 5'-GAATGTCTGAGGACAAGCCACAAG-3'and 5'-TGGGCACCAATATCAAGTCCAA-3', Gene expressions were performed in triplicate, and the consequence was calculated by $2^{-\triangle} \triangle \mathrm{CT}$ method.

\section{Protein extraction and western blot}

The cellar proteins were extracted by a standard RIPA lysis buffer(Sigma Chemicals, USA). $30-40 \mu \mathrm{g}$ protein isolates were denatured by 8-12\% SDS-PAGE and consequently transferred onto PVDF membranes (Millipore, USA), which was blocked by TBST with $5 \%$ non-fat milk for about 1 hour at room temperature, then incubated with primary antibodies solution (AnxA1,1:500;E-cadherin, 1:1000; Snail1, 1:500; N-cadherin, 1:1000; Vimentin, 1:500 and GAPDH)overnight at $4{ }^{\circ} \mathrm{C}$, followed by combining with secondary antibodies. Protein bands were examined by enhanced chemiluminescence (Advasta, USA).

\section{Mouse xenograft model}

Ten BALB/c nude mice aging 6 to 8 weeks were randomly divided into two groups, five of them were injected with shScramble cells $\left(5 \times 10^{5} \mathrm{BC}\right.$ cells $)$ and five of them were with AnxA1-transfected MDA-MB231 cells $\left(5 \times 10^{5} \mathrm{BC}\right.$ cells)at mammary fat pads. Two weeks later the two groups mice were 
intraperitoneally given injection of control ( $0.1 \%$ DMSO solution) or $2 \mathrm{mg} / \mathrm{kg}$ UA respectively (dissolved in $0.1 \%$ DMSO solution) every two days for two weeks. Then the mice were killed at the 28 th days. The excised tumor were assessed by immunohistochemistry.

\section{Immunofluorescence analysis}

Cells were fixed with $4 \%$ formalin and washed with PBST (PBS and $0.5 \%$ Triton X-100) three times, then incubating with $3 \% \mathrm{BSA}$ for $30 \mathrm{~min}$ at $37^{\circ} \mathrm{C}$, followed by staining with primary antibody at $4^{\circ} \mathrm{C}$ overnight and treated with a fluorescence-conjugated secondary antibody at $37^{\circ} \mathrm{C}$ for 1 hour, subsequently stained the nuclei using DAPI, and images were captured with a laser scanning confocal microscope.

\section{Immunohistochemical analysis}

Tissue sections were deparaffinized, rehydrated, incubated with 5\% BSA and labeled with primary antibody at $4{ }^{\circ} \mathrm{C}$ overnight. Then slides were stained with the peroxidase conjugated-biotin streptavidin complex for 1 hour and counterstained with hematoxylin for 30s, then covered.

\section{Statistical analysis}

Statistical data was analyzed by SPSS19.0 software and GraphPad Prism 5. Data were presented as mean \pm standard deviations (SD). Student's t-test was evaluated to the difference of two groups. One-way ANOVA was used to compare multiple groups. $P<0.05$ was considered statistical difference.

\section{Results}

\section{UA suppresses the proliferation of breast cancer cells}

Figure 1A shows a chemical structure of ursolic acid. To find the optimum suppression concentration of UA on human breast cancer MCF-7 and MDA-MB-231 cell lines , different concentrations $(0,5,10,15,20$, 30 and $40 \mu \mathrm{M}$ ) of UA were performed for $24 \mathrm{~h}$ and $48 \mathrm{~h}$ and the viability was detected by CCK-8 assays(Fig. 1B,1C). The 50\% growth inhibitory concentrations (IC50) were about $23 \mu \mathrm{M}$ and $28 \mu \mathrm{M}$ in MCF-7 and MDA-MB-231 for $24 \mathrm{~h}$ respectively. Based on these results, A dosage of $25 \mu \mathrm{M}$ ursolic acid was performed for subsequent experiments. UA significantly inhibited cell viability with the elevated concentration and the effects of growth inhibition were also connected with incubation time at a given UA concentration. UA treatment led to a more decreased number of cells in $48 \mathrm{~h}$ than $24 \mathrm{~h}$. These data demonstrate that UA suppresses cell growth in a dose- and time-dependent manner.

\section{UA reinforces the attenuation effect of AnxA1 knockdown on breast cancer cell stemness.}

BCSC are identified as a subpopulation of $\mathrm{CD} 44+/ \mathrm{CD} 24^{-/ \text {low }}$ cells, additional markers such as ALDH1, Oct4 and Sox2 are also used recently. Sphere formation assays are a accepted method to detect the behavior of BSCD[29]. In order to investigate the influences of AnxA1 on breast cancer stem cell, first we knocked down endogenous AnxA1 with siRNA oligonucleotidesin in MCF-7 and MDA-MB-231 cells. The 
expression levels of AnxA1 mRNA1 and AnxA1 mRNA2 were obviously reduced compared to the level of the control group cells (Fig. 2c). Similar results were observed in protein level by western blotting in evidence(Fig. 2a,2b). Immunofluorescence assays further confirmed the downregulation of AnxA1 expression in MDA-MB-231 cells(Fig. 2d), furthermore, we discovered that knockdown of AnxA1 made morphological changes of breast cancer cells from spindle mesenchymal phenotype to cuboidal epithelial phenotype. In addition, AnxA1 knockdown significantly inhibited the mammosphere forming ability(Fig. 2F-I), including the quantity and size, compared with the control group. The protein expression of main cancer stem cell markers (ALDH1, Oct4 and Sox2) were detected in MDA-MB-231 cells (Fig. 2e). Western blot revealed that the expression of the three markers were decreased in cells transfected with AnxA1 shRNA and/ or treatment with UA for $48 \mathrm{~h}$, compared with the control cells. Thus, we hold the opinion that AnxA1 knockdown could inhibit mammosphere formation and reduce the stemness of MDAMB-231 cells, while UA could reinforce these function.

\section{UA reverses the migration and invasion effect of breast cancer cell promoted by AnXA1}

Recent researchers have shown that the expression of AnxA1 in tumors is tissue specific, highly expression in colorectum, lung, pancreas, liver and glioma, downregulation or deletion in cervix, thyroid, larynx, prostate, head and neck, but the expression of AnxA1 in breast cancer is still controversial[30].To better understand the role of AnxA1 on BC, we detected the matrix metalloproteinases(MMP2 ,MMP9) expression by western blot(Fig. 3e), which in charge of the degradation of the extracellular matrix (ECM), play an important role in tumor invasion and metastasis, and additionally some functional tests were carried out, such as wound healing(Fig. 3a,3b) and matrigel invasive assays(Fig. 3c,3d). The western blot analysis on MMP2 and MMP9 following AnxA1 downregulation and/ or treatment with UA indicated that the proteins were decreased in experimental group compared to control group. Furthermore, wound healing and matrigel invasive assays revealed that the depletion of AnxA1 reduced the migratory and invasive potential of $B C$ cells. These findings imply that $A n x A 1$ enhances the invasion and migration of $B C$ cells, especially in MDA-MB-231 cells, while UA can reverse the alterations.

\section{Depletion of AnxA1 simultaneous UA treatment impede breast cancer cell epithelial-mesenchymal transition(EMT)}

Epithelial-mesenchymal transition (EMT) is a transformation process mandatory for the local and distant progression of many malignant tumors[31]. It's characterized by increased production of mesenchymal markers (e.g. N-cadherin) and decreased expression of epithelial markers (e.g. E-cadherin). To determine the effect of AnxA1 on EMT. We examined the expression analysis of EMT markers by western blot.As shown in Fig. $4 a$ and $b$, knockdown of AnxA1 reduced $\mathrm{N}$-cadherin expression, but increased E-cadherin expression. The similar results was examined in qRT-PCR assay(Fig. 4c). Immunofluorescence assay was also used to evaluate the role of downregulation of AnxA in EMT, the expression levels of E-cadherin were elevated, while that of Vimentin, $\mathrm{N}$-cadherin and Snail were reduced compared with the control group(Fig. 4d). When UA was extra added to the two groups, the results were more obvious(Fig. 4e). These 
data reveal that the downregulation of AnxA1 suppresses breast cancer cell EMT, while UA can strengthen the process.

\section{UA treatment targets AnxA1 to inhibit proliferation and accelerate apoptosis in MDA-MB-231 cells}

To determine the antiproliferative effect, NC siRNA or AnxA1 siRNA group of MDA-MB-231 cell lines were detected by UA at different concentrations $(0,5,10,15,20,30$ and $40 \mu \mathrm{M})$ with CCK-8 assays at $24 \mathrm{~h}$ and $48 \mathrm{~h}(\mathrm{Fig} .4 \mathrm{~A}, \mathrm{~B})$. The results showed that the viability of AnxA1-depletion group was more sensitive to UA than that of NC group and as the extended treatment time of UA, the viability went down. Western blot analysis showed the decreased expressions of apoptosis-related biomarkers(e.g.Bcl-2) following depletion of AnxA1 in MDA-MB-231 cell and UA strengthened the process(Fig. 4C). The results that AnxA1 knockdown simultaneous UA treatment can accelerate apoptosis were also confirmed by flow cytometry analysis in MDA-MB-231 cell(Fig. 4D). Together, these results suggest that depletion of AnxA1 accompanied by UA treatment can exert the effect of antiproliferation and proapoptosis to breast cancer cells.

\section{The combination of AnxA1 knockdown and UA treatment inhibits tumorigenicity}

To further evaluate the anti-tumor effect of combination of AnxA1 downregulation and UA treatment on tumor growth in vivo, we built a tumor xenograft models by subcutaneous injection of MDA-MB- 231 breast cancer cells into the mammary gland of nude mice, which had been transfected with AxnA1 shRNA or scramble shRNA, then intraperitoneally injected with control or with UA respectively every two days for two weeks (Fig. 6A). Tumor volume and weight were measured and analyzed. We found that both volume and weight of AnxA1 shRNA group decreased(Fig. 6B,C). The combination of AnxA1 knockdown and UA treatment obviously inhibits the proliferation marker Ki-67, stemness marker Oct4 and proapoptosis marker Bcl2 in the xenograft tissues as seen by immunohistochemical staining(Fig. 6D).

\section{UA strengthens the inhibition of AnxA1 knockdown to downregulation of wnt/ $\beta$-catenin pathway on MDA- MB-231}

The wnt signaling plays important roles in embryonic development and tissue homeostasis[32]. Canonical wnt/ $\boldsymbol{\beta}$-catenin signaling is one of the main signaling related with regulation of stem cell in many tissues, where numerous of its functions maybe come from effects on stem or progenitor cells. Emerging data from a wide range of human tumor researches has demonstrated that the wnt/ $\boldsymbol{\beta}$-catenin pathway is often activated and may modulate tumor in part by regulation of cancer cells with stem-like cell properties[33]. Given this reason, we examined some pivotal signaling markers in wnt/ $\beta$-catenin pathway to disclose the potential mechanism of the inhibitory effects on BCSCs. We found that the expressions of p-GSK and $\beta$-catenin were obvious downregulated by knockdown of AnxA1 and treatment with UA by western blot and qRT-PCR assays, while no significant change in the expression of GSK(Fig. 7A,B). In xenogrft tissue the expression of E-cadherin was increased and Vimentin , $\beta$-catenin were decreased. These data suggest that UA strengthens the inhibition of AnxA1 knockdown to downregulation of wnt/ $\beta$-catenin pathway on MDA-MB-231. In other words, the possible mechanism of 
the inhibition effect of ursolic acid on breast cancer stem cells through downregulating AnxA1 maybe by affecting the EMT process and the wnt/ $\beta$-catenin signaling pathway.

\section{Discussion}

Breast cancer is a heterogeneous disease, usually categorised based on histological subtypes that divided into at least 17 distinct histological types[34], and molecular subtypes identified by gene expression analysis classified five molecular subtypes, namely normal-like, luminal A, luminal B, HER2 overexpressing and basal-like (BL) [35-36]. The treatment options and prognosis of breast cancer vary greatly with subtype. In the present study, two breast cancer lines were used, MCF-7 cell line is luminal A subtype with $\mathrm{ER}+, \mathrm{PR}+/-/ \mathrm{HER} 2$ - and lowly invasive, MDA-231 cell line represents triple negative breast cancer (TNBC) with ER-, PR-,HER2- and highly invasive[37]. AnxA1 is a kind of membrane associated protein, has showed to be abnormally expressed in different cancers. It was highly expressed in colorectal, hepatocellular, pancreatic and lung cancer and high level of AnxA1 has positive correlation with disease severity and higher pathologic tumor grade. However, reduced AnxA1 expression was more prone to develop in prostate,cervical, esophageal and laryngeal cancer, and the expression of AnxA1 was negatively correlated with tumor development[38]. These studies demonstrate that AnxA1 might have different effects in different tumors and reveal the heterogeneity and complexity of tumors. However, AnxA1 has not been well examined in breast cancer, the biological role and regulation of AnxA1 is still unclear. In this study we discovered AnxA1 was significantly upregulated in the MDA-MB-231 cells by western blot, while a lower level in MCF-7. Downregulation of AnxA1 reduces the proliferation of breast cancer cells and promotes cell apoptosis. Furthermore, the inhibition of AnxA1 by siRNA significantly attenuates the invasion and migration of breast cancer cells. This suggests that AnxA1 participate in carcinogenesis and/or progression of breast cancer and may act as a potential marker for breast cancer as well as a novel treatment.

In addition, we demostrate for the first time that wnt/ $\beta$-catenin pathway was involved in the regulation by AnxA1. Wnt signaling pathway plays a pivotal role in embryogenesis and tumorigenesis, stem cell regeneration as well[39]. Minashima T and Kirsch T[40]reported that AnxA6 together with cytosolic $\mathrm{Ca}^{2+}$ could inhibit the canonical wnt/ $\beta$-catenin pathway in articular chondrocytes by competing with the plasma membrane association of the Wnt signal complex that contains Dvl, axin and adenomatosis polyposis coli (APC). Formation of the signal complex and its association plasma membrane results in the inactivation of GSK3ßand the subsequent accumulation of $\beta$-catenin in nucleus. Annexins are cytoplasmic proteins in a variety of cell types,which can interplay with phospholipids and bind with cytomembrane at different $\mathrm{Ca}^{2+}$ concentrations, that means AnxA1 can interact with the Wnt signal complex as well.Rubinstein MR et al [41]elucidates AnxA1 is a previously unrecognized modulator of Wnt/ $\beta$-catenin signal and a novel biomarker for colon cancer recurrence, he proposed a "two-hit" model for colorectal cancer progression, that is, low level of AnxA1 results in weak binding of FadA to E-cadherin while increased AnxA1 level accompanied by enhancing FadA binding, forming FadA-E-cadherinAnnexin $A 1-\beta$-catenin complex, subsequent activation of $\beta$-catenin, resulting in acceleration of cancer 
progression. Our data suggest the knockdown of AnxA1 can inhibit wnt/ $\beta$-catenin pathway at both the mRNA and protein levels in MDA-MB-231 cells. This demonstrated that AnxA1 was involved in the regulation of wnt signaling.

EMT is a dynamic process that can be regulated and reversed by various factors, accompanied by alterations of morphology, function, protein expression profiles and acquisition of stemness. Our study showed the knockdown AnxA1 increased the expression of E-cadherin (epithelial marker), contrast by the decreased expression of Vimentin, N-cadherin, snail(mesenchymal markers) and MMP-2,MMP-9 (metastasis marker) in AnxA1-overexpressing MDA-MB-231 cells. These data demonstrated that depletion of AnxA1 contributes to the reverse process from EMT to MET in breast cancer and might facilitates an EMT-like switch, which is in agreement with the EMT effect of AnxA1 in breast cancer [42]. We also revealed that the knockdown of AnxA1 simultaneously inhibits EMT and BC cell stemness. This confirms that cancer cells originate stemness through EMT, meanwhile, AnxA1 reinforces MDA-MB-231 cell stemness and possibly by enhancing the EMT process. A complex network of signaling pathways(such as wnt/ $\beta$-catenin ) is involved in the induction of EMT in BCSC[43]. When Wnt signaling is activated, it can stabilize the downstream effector $\beta$-catenin and result in its accumulation to translocation into the nucleus to activate the transcription of wnt target genes[44]. This leads to subsequent snail increase and E-cadherin reduction causing development of EMT, which explained the depletion of AnxA1 resulting in the inactivation of wnt signal simultaneous attenuation of EMT.

TNBCs represent $<15 \%$ of all breast cancers and show enhanced aggression with poor survival [44]. It is consistently reported that TNBC cells are prone to showing signatures of cancer stem cell (CSC) at functional, molecular, and transcriptional levels. In recent decades, designing CSC targeted therapies have exhibited effects on TNBC in preclinical development or in clinical trials. It is involved in restraining the essential Wnt signaling pathways that regulate CSC renewal and maintenance in oncogenesis. Inversely, activating Wnt signaling can trigger the "stemness". Here, we found that silencing of AnxA1 suppresses mammosphere formation, reduced expression of CSC associated markers ALDH1, Oct4 and Sox2, and suppressed the growth of tumor xenograft in vitro. Taken together, silencing of AnxA1 inactivate wnt/ $\beta$ catenin pathway and repress MDA-MB-231 cancer stem cells through inhibiting expression of Sox2, ALDH1 and Oct4, simultaneously MET.

Ursolic acid (UA), a plant extract from Chinese herbs as well as edible vegetables, exhibits a potent anticancer activity in various tumor cells. Here, we presented knockdown of AnxA1 in combination with UA therapy could inhibit proliferation, migration and invasion, induce apoptosis, inactivate wnt signaling, decrease the level of stem cell markers and transform EMT to MET in BC cells. Altogether, our results indicate that depletion of AnxA1 may be a promising novel way for tumor therapy in combination with UA

\section{Conclusion}


In conclusion, we have identified that AnxA1 was highly expressed in MDA-MB-231 cell line and played a multifaceted role in breast cancer, UA is an effective inhibitor of breast cancer stem cells. We demonstrate for the first time that a combination of targeting AnxA1 and UA can specifically inhibit BCSCs, in connection with downregulation of the wnt/ $\beta$-catenin signal pathway and reversing EMT. A combination of targeting AnxA1 and UA has been emerging as a promising therapeutic strategy to inhibit BC in the future, and clearly warrants further study and development.

\section{Abbreviations}

UA:Ursolic acid; AnxA1:Annexin A1; BC:Breast cancer; BCSC: $:$ Breast cancer stem cells; CSC $_{S}$ : Cancer stem cells; TNBCs:Triple negative breast cancer; qRT- PCR:Real-time quantitative polymerase chain reaction; EMT:Epithelial-mesenchymal transition; MET:Mesenchymal-epithelialtransition; CCK-8:Cell Counting Kit-8; ALDH1:Aldehyde dehydrogenase isoform 1; DMSO:Dimethyl sulfoxide; PBS: Phosphate buffered saline; FBS: fetal bovine serum

\section{Declarations}

\section{Authors'contributions}

L.L. conceived and designed the experiment and S.F.drafted the manuscript.

S.F.,R.X.,H.Z.,Q.Z.,Y.L.,M.W.,H.W.,X.Y., Z.H.,X.S. and Y.W.performed the experiment. J.M., Y.H.,B.W. and B.S.participated in all statistical analysis. B.S. and L.L. revised the manuscript. All the authors read and approved the final manuscript.

\section{Funding}

This work was supported by the Dalian Science and Technology Innovation Fundation (2019J12SN53)and the Key Laboratory of Tumor Stem Cell Research of Liaoning Province.

\section{Availability of data and materials}

All the data analyzed or generated during the study are included in this published article.

\section{Ethics approval and consent to participate}

This research was reviewed and approved by the Ethical Committee and Institutional Review Board of Dalian Medical University (No. AEE17046) and all participants in the study was informed consent.

\section{Consent for publication}

Not applicable.

\section{Competing interests}


The authors declare no conflicts of interest

\section{References}

1.Bray F, Ferlay J, Soerjomataram I, Siegel RL, Torre LA, Jemal A. Global cancer statistics 2018:GLOBOCAN estimates of incidence and mortality worldwide for 36 cancers in 185 countries.

CA Cancer J Clin. 2018,68(6):394-424.

2.Harbeck N, Penault-Llorca F, Cortes J, Gnant M, Houssami N, Poortmans P, et al.Breast cancer.Nat Rev Dis Primers. 2019 Sep 23;5(1):66.

3.Velasco-Velázquez MA, Popov VM, Lisanti MP, Pestell RG. The role of breast cancer stem cells in metastasis and therapeutic implications.Am J Pathol. 2011 Jul;179(1):2-11.

4.Ricardo S, Vieira AF, Gerhard R, Leitão D, Pinto R, Cameselle-Teijeiro JF, et al. Breast cancer stem cell markers CD44, CD24 and ALDH1: expression distribution within intrinsic molecular subtype. J Clin Pathol. 2011;64(11):937-46.

5.Beck B, Blanpain C. Unravelling cancer stem cell potential. Nat Rev Cancer.2013;13:727-38.

6.Al-Ejeh F, Smart CE, Morrison BJ, Chenevix-Trench G, Lopez JA, Lakhani SR, et al. Breast cancer stem cells: treatment resistance and therapeutic opportunities. Carcinogenesis. (2011) 32:650-8.

7.Vásquez-Bochm LX, Velázquez-Paniagua M, Castro-Vázquez SS, Guerrero-Rodríguez SL, MondragonPeralta A, De La Fuente-Granada M, et al. Transcriptome-based identification of lovastatin as a breast cancer stem cell-targeting drug . Pharmacol Rep. 2019 Jun;71(3):535-544.

8.Yin R, Li T, Tian JX, Xi P, Liu RH.Ursolic acid, potential anticancer compound for breast cancer therapy. Crit Rev Food Sci Nutr. 2018 Mar 4;58(4):568-574.

9.Baricevic D1, Sosa S, Della Loggia R, Tubaro A, Simonovska B, Krasna A, et al.Topical antiinflammatory activity of Salvia officinalis L. leaves: the relevance of ursolic acid.J Ethnopharmacol. 2001 May;75(2-3):125-32.

10.Shanmugam MK1, Nguyen AH, Kumar AP, Tan BK, Sethi G.

Targeted inhibition of tumor proliferation, survival, and metastasis by pentacyclic triterpenoids: potential role in prevention and therapy of cancer. Cancer Lett. 2012 Jul 28;320(2):158-70.

11.Woźniak $Ł$, Skąpska S, Marszałek K.Ursolic Acid--A Pentacyclic Triterpenoid with a Wide Spectrum of Pharmacological Activities.Molecules. 2015 Nov 19;20(11):20614-41.

12.Seo DY, Lee SR, Heo JW, No MH, Rhee BD, Ko KS, et al.Ursolic acid in health and disease.Korean J Physiol Pharmacol. 2018 May;22(3):235-248. 
13.Jaman MS, Sayeed MA. Ellagic acid, sulforaphane, and ursolic acid in the prevention and therapy of breast cancer: current evidence and future perspectives. Breast Cancer. 2018 Sep;25(5):517-528.

14.Ko EY, Moon A.Natural Products for Chemoprevention of Breast Cancer. J Cancer Prev. 2015 Dec;20(4):223-31.

15.Shan JZ, Xuan YY, Ruan SQ, Sun M.Proliferation-inhibiting and apoptosis-inducing effects of ursolic acid and oleanolic acid on multi-drug resistance cancer cells in vitro. Chin J Integr Med. 2011 Aug;17(8):607-11.

16.K.H. Kim, H.S. Seo, H.S. Choi, I. Choi, Y.C. Shin, S.G. Ko. Induction of apoptotic cell death by ursolic acid through mitochondrial death pathway and extrinsic death receptor pathway in MDA-MB-231 cells. Arch Pharm Res. 2011 Aug;34(8):1363-72.

17.Shishodia S, Majumdar S, Banerjee S, Aggarwal BB. Ursolic acid inhibits nuclear factor-kappaB activation induced by carcinogenic agents through suppression of IkappaBalpha kinase and p65 phosphorylation: correlation with down-regulation of cyclooxygenase 2, matrix metalloproteinase 9 , and cyclin D1.Cancer Res. 2003 Aug 1;63(15):4375-83.

18.M.K. Shanmugam, X. Dai, A.P. Kumar, B.K. Tan, G. Sethi, A. Bishayee. Ursolic acid in cancer prevention and treatment: molecular targets, pharmacokinetics and clinical studies. Biochem Pharmacol. 2013 Jun 1;85(11):1579-87.

19.Shao G, Zhou H, Zhang Q, Jin Y, Fu C. Advancements of Annexin A1 in inflammation and tumorigenesis.Onco Targets Ther. 2019 Apr 30;12:3245-3254.

20.Rescher U, Gerke V. Annexins - unique membrane binding proteins with diverse functions. J Cell Sci. 2004;117:2631-9.

21.Futter CE, White IJ. Annexins and endocytosis. Traffic. 2007;8:951-8.

22.McArthur S, Yazid S, Christian H, Sirha R, Flower R, Buckingham J, et al.Annexin A1 regulates hormone exocytosis through a mechanism involving actin reorganization. FASEB J. 2009;23:4000-10.

23.Mu D, Gao Z, Guo H, Zhou G, Sun B. Sodium butyrate induces growth inhibition and apoptosis in human prostate cancer DU145 cells by upregulation of the expression of annexin A1. PLoS One. 2013 Sep 23;8(9):e74922.

24.Bizzarro V, Fontanella B, Franceschelli S, Pirozzi M, Christian H, Parente L, et al. Role of Annexin A1 in mouse myoblast cell differentiation. J Cell Physiol. 2010;224:757-65.

25.Mussunoor S, Murray GI. The role of annexins in tumour development and progression. J Pathol. 2008 Oct;216(2):131-40. 
26.Guo C, Liu S, Sun MZ. Potential role of ANXA1 in cancer. Future Oncol.2013;9:1773-93.

27.Yi M, Schnitzer JE. Impaired tumor growth, metastasis, angiogenesis and wound healing in annexin A1-null mice. Proc Natl Acad Sci U S.2009;106:17886-91.

28.R. Biaoxue, C. Xiguang, Y. Shuanying, Annexin A1 in malignant tumors: current opinions and controversies.Int J Biol Markers. 2014 Mar 24;29(1):e8-20.

29.Crabtree JS, Miele L. Breast Cancer Stem Cells.Biomedicines. 2018 Jul 17;6(3).

30.Shao G, Zhou H, Zhang Q, Jin Y, Fu C. Advancements of Annexin A1 in inflammation and tumorigenesis. Onco Targets Ther. 2019 Apr 30;12:3245-3254.

31.Scheau C, Badarau IA, Costache R, Caruntu C, Mihai GL, Didilescu AC, et al. The Role of Matrix Metalloproteinases in the Epithelial-Mesenchymal Transition of Hepatocellular Carcinoma.Anal Cell Pathol (Amst). 2019 Nov 26;2019:9423907

32.Blagodatski A, Poteryaev D, Katanaev VL.Targeting the Wnt pathways for therapies. Mol Cell Ther. 2014 Sep $11 ; 2: 28$.

33.Many AM, Brown AM. Both canonical and non-canonical Wnt signaling independently promote stem cell growth in mammospheres. PLoS One. 2014 Jul 14;9(7).

34.H.P. Sinn, H. Kreipe, A brief overview of the WHO classification of Breasttumors, 4th edition, focusing on issues and updates from the 3rd edition.Breast Care (Basel). 2013 May;8(2):149-54.

35.T. Sorlie, C.M. Perou, R. Tibshirani, T. Aas, S. Geisler, H. Johnsen, et al. Gene expressionpatterns of breast carcinomas distinguish tumor subclasses with clinicalimplications. Proc Natl Acad Sci U S A. 2001 Sep 11;98(19):10869-74.

36.C.M. Perou, T. Sorlie, M.B. Eisen, M. van de Rijn, S.S. Jeffrey, C.A. Rees, et al. Molecular portraits of human breast tumours. Nature. 2000 Aug 17;406(6797):747-52.

37.Tu Y, Johnstone CN, Stewart AG. Annexin A1 influences in breast cancer: Controversies on contributions to tumour, host and immunoediting processes. Pharmacol Res. 2017 May;119:278-288.

38.Sheikh MH, Solito E. Annexin A1: Uncovering the Many Talents of an Old Protein. Int J Mol Sci. 2018 Mar 31;19(4).

39.Patel S, Alam A, Pant R, Chattopadhyay S. Wnt Signaling and Its Significance Within the Tumor Microenvironment: Novel Therapeuticlnsights. Front Immunol. 2019 Dec 16;10:2872.

40.Minashima T, Kirsch T. Annexin A6 regulates catabolic events in articular chondrocytes via the modulation of NF-KB and Wnt/ß-catenin signaling. PLoS One. 2018 May 17;13(5). 
41.Rubinstein MR, Baik JE, Lagana SM, Han RP, Raab WJ, Sahoo D, et al.Fusobacterium nucleatum promotes colorectal cancer by inducing Wnt/ $\beta$-catenin modulator Annexin A1.EMBO Rep. 2019 Apr;20(4).

42.de Graauw M, van Miltenburg MH, Schmidt MK, Pont C, Lalai R, Kartopawiro J, et al. Annexin A1 regulates TGF-beta signaling and promotes metastasis formation of basal-like breast cancer cells. Proc Natl Acad Sci U S A. 2010 Apr 6;107(14):6340-5.

43.M.A. Huber, N. Kraut, H. Beug. Molecular requirements for epithelial-mesenchymal transition during tumor progression. Curr Opin Cell Biol. 2005 Oct;17(5):548-58.

44.Y. Wang, B.P. Zhou. Epithelial-mesenchymal transition in breast cancer progression and metastasis.Chin J Cancer. 2011 Sep;30(9):603-11.

\section{Figures}

A

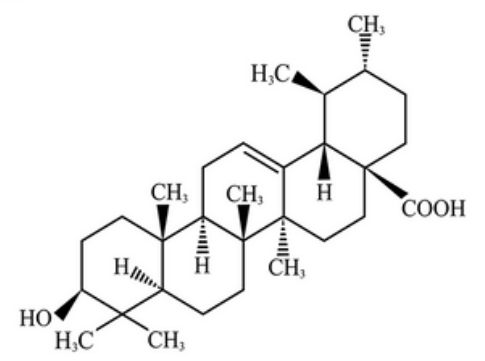

MCF-7

B

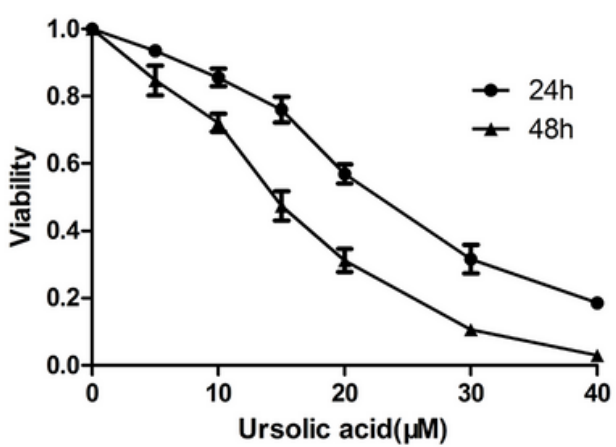

C

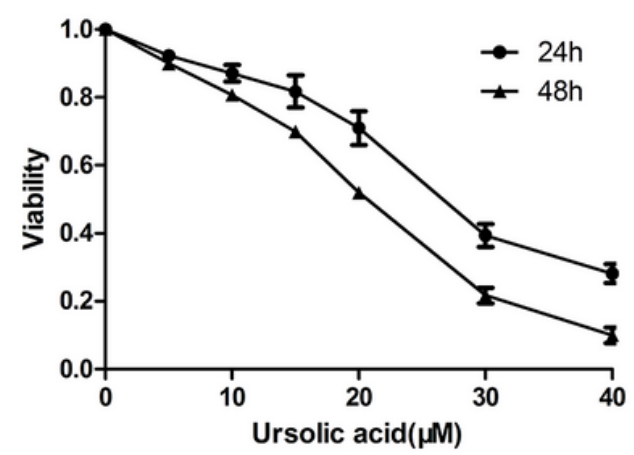

\section{Figure 1}

UA suppresses the proliferation of breast cancer cells . (A)Chemical structures of UA. (B ,C)CCK-8 cell assays of ursolic acid on the viability in MCF-7 and MDA-MB-231 cells $(0,5,10,15,20,30$ and $40 \mu \mathrm{M} ; 24$ $\mathrm{h}$ and $48 \mathrm{~h}$ ). All data are represented as the means \pm S.D. of three independent experiments. *, $p<0.05$; $\star *$, $p<0.01$. 
A

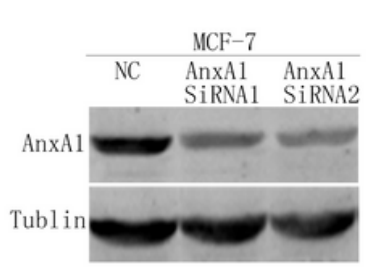

D

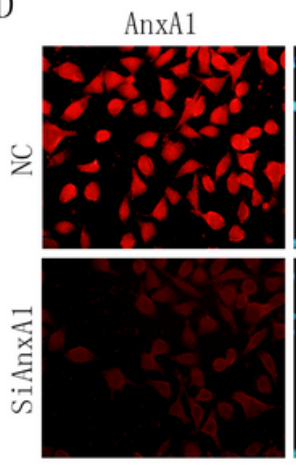

DAPI

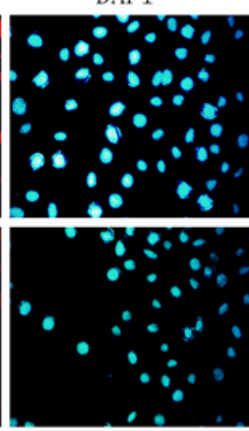

F

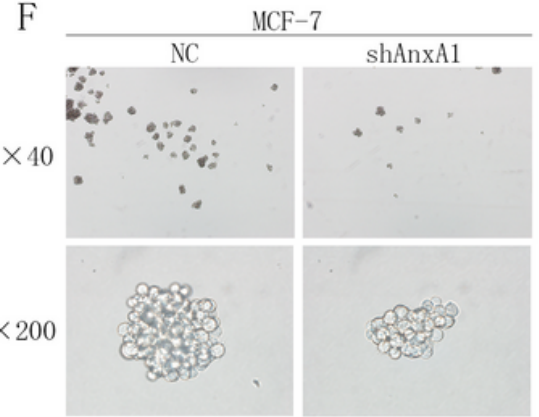

B

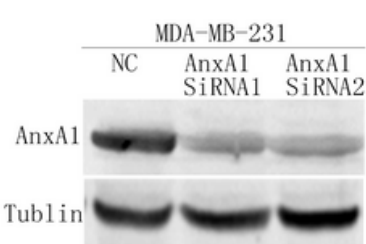

Merge

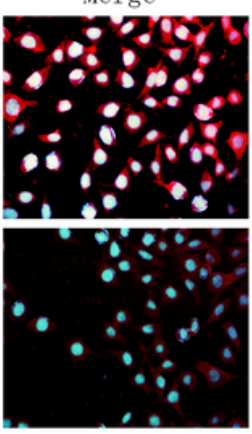

E
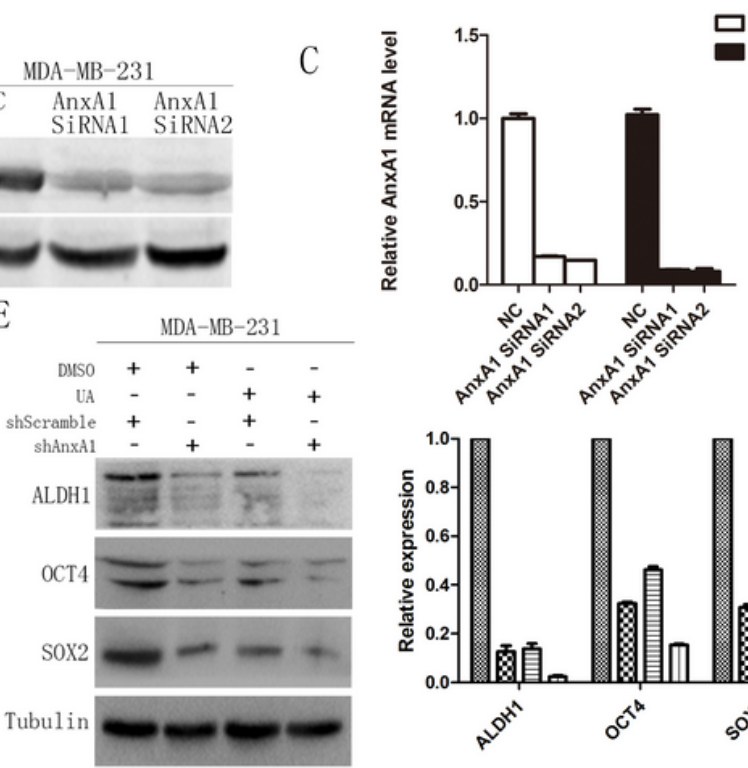

MDA-MB-231

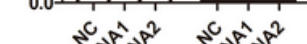

G MCF-7

H

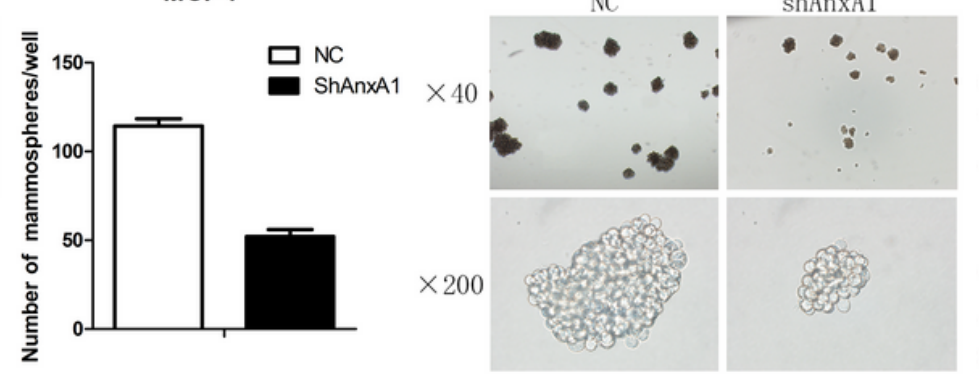
I

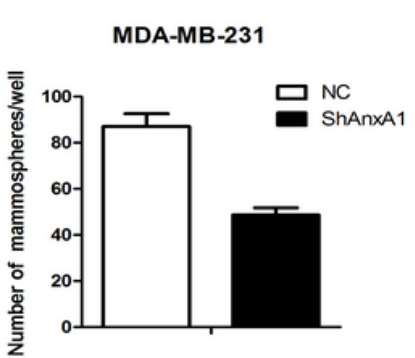

Figure 2

UA reinforces the attenuation effect of AnxA1 knockdown on breast cancer cell stemness . (A,B)MCF-7 and MDA-MB-231 cells were transfected with AnxA1 siRNA or NC siRNA for $48 \mathrm{~h}$. Western blotting analysis of AnxA1 knockdown efficiency in MCF-7 and MDA-MB-231 cells. (C)Real-time quantitative PCR analysis of AnxA1 knockdown efficiency in MCF-7 and MDA-MB-231 cells. (D)Immunofluorescence staining of MDA-MB-231 cells after transfection with NC siRNA or AnXA1 siRNA. (E) Western blot analysis of ALDH1, Oct4 and Sox2 expression of transfection with AnxA1 shRNA and/ or treatment with UA. (F-I) Sphere formation assays after downgrading AnxA1 in MCF-7 and MDA-MB-231 cells. (original magnification, $\times 40$ or $\times 200$ ). All data are expressed as the means \pm S.D. of values from triplicate experiments. ${ }^{*}, \mathrm{p}<0.05 ; * \star, p<0.01$. 
A
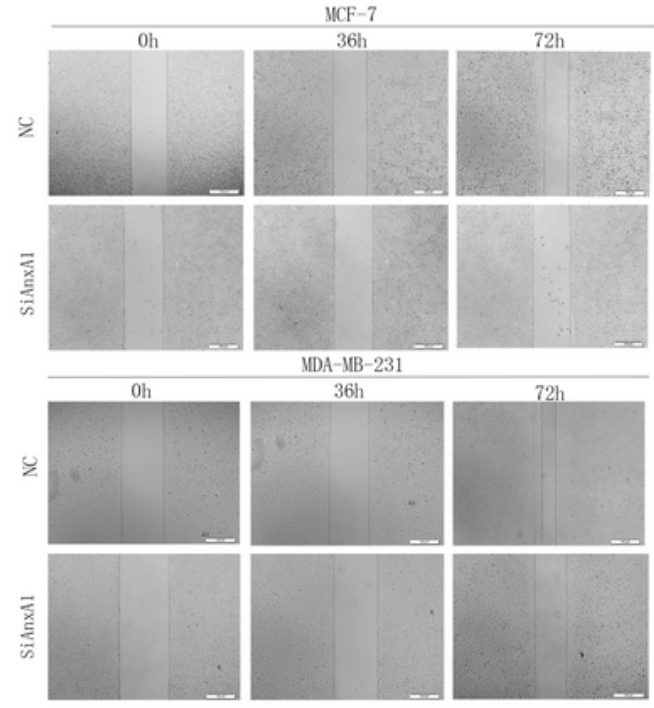

C

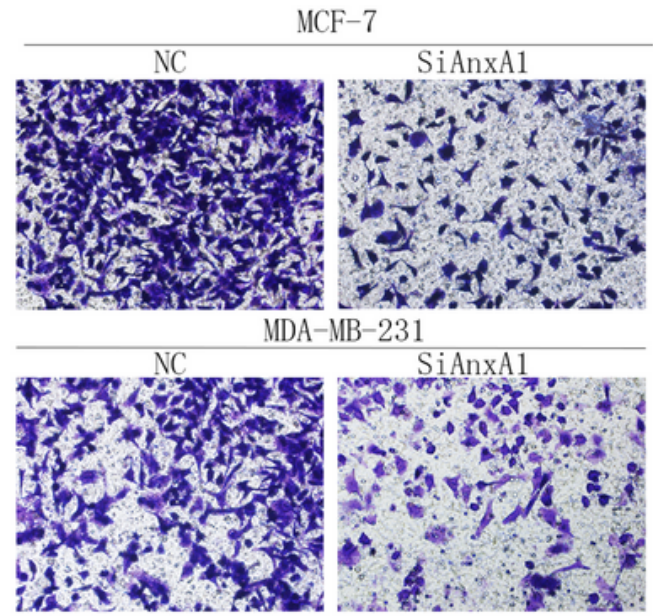

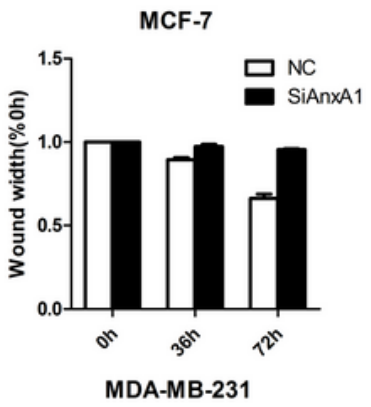

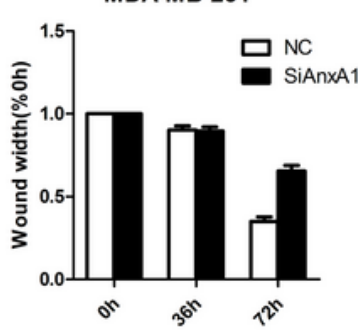

MCF-7

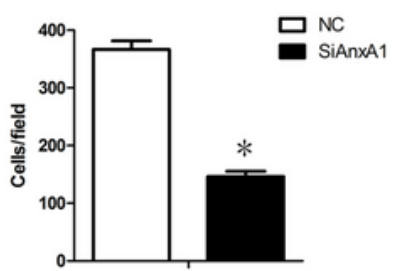

MDA-MB-231

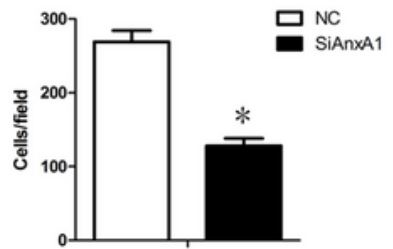

$\mathrm{E}$

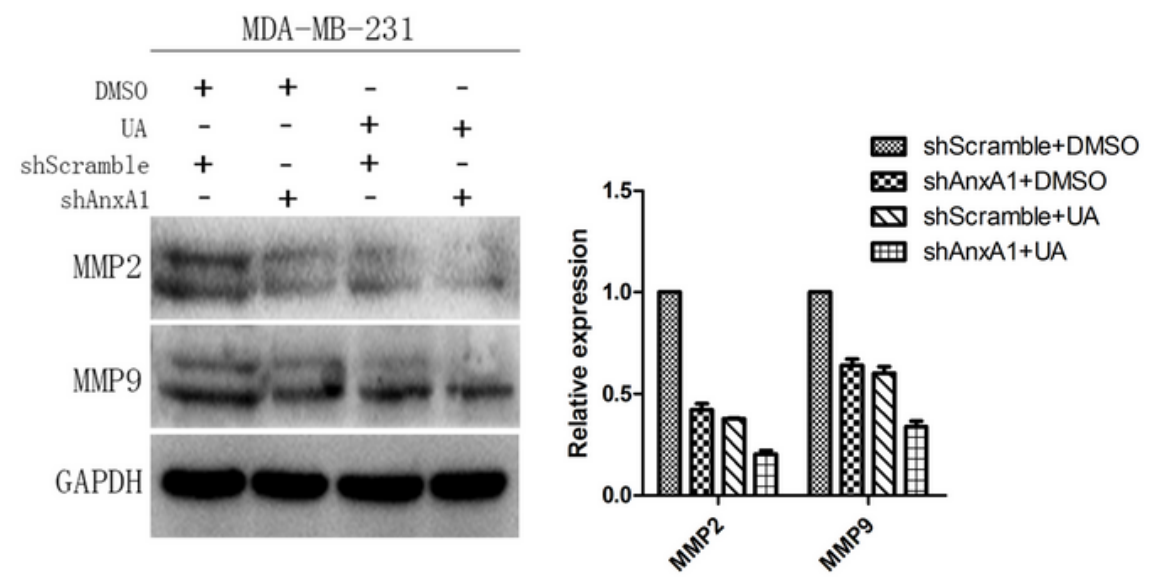

Figure 3

UA reverses the migration and invasion effect of breast cancer cell promoted by AnxA1. $(A, B)$ Wound healing assays were performed to analyze cell migration with transfected of AnxA1 siRNA or NC siRNA for $48 \mathrm{~h}$. $(\mathrm{C}, \mathrm{D})$ Cell invasion were determined by matrigel transwell assay. All data represent the mean $\pm \mathrm{SD}$ in the three independent experiments. (E)Western blot analysis of MMP-2,MMP-9 expression of transfection with AnxA1 shRNA and/ or treatment with UA *P $<0.05$, ** $\mathrm{P}<0.01$, *** $\mathrm{P}<0.001$. 

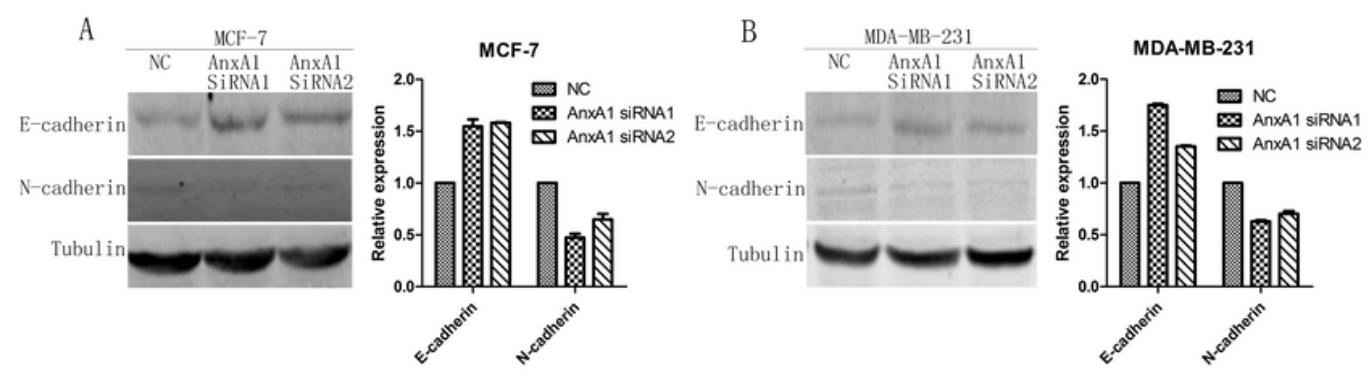

C
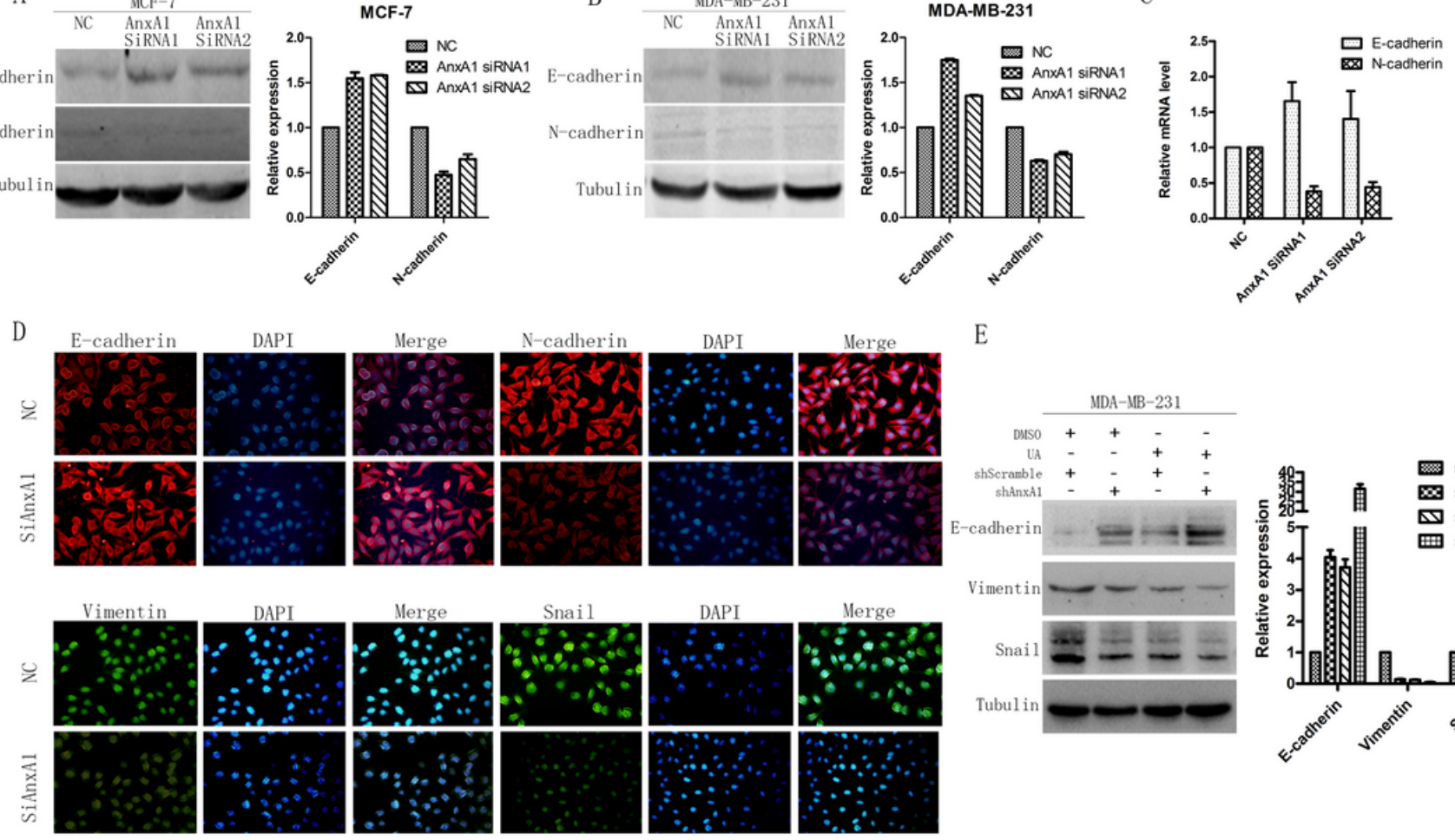

E

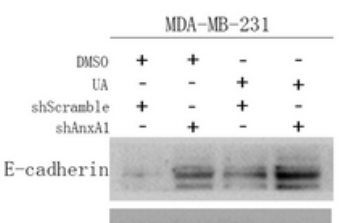

Vimenti
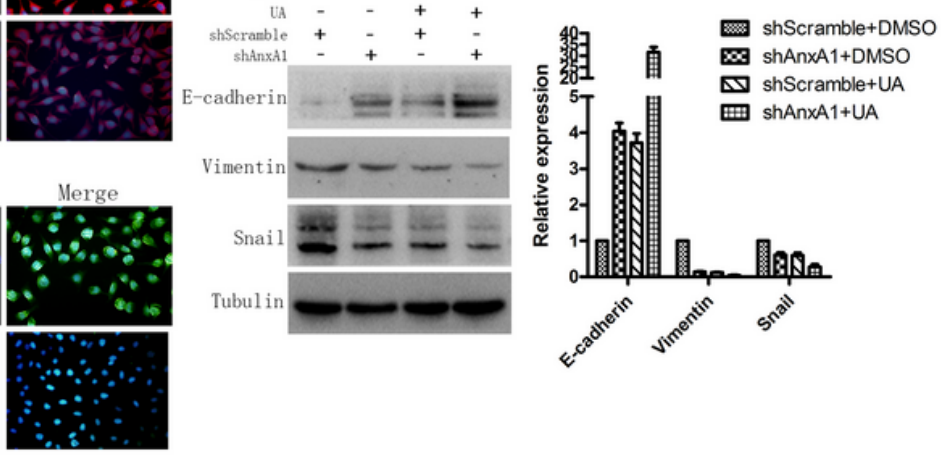

\section{Figure 4}

Effect of AnxA1 simultaneous UA on breast cancer cell EMT. (A, B).Downregulation of AnxA1 reduced Ncadherin level and elevated E-cadherin expression in MDA-MB-231 and MCF-7 cells by western blot.(C) Real-time quantitative PCR analysis of AnxA1 knockdown efficiency in MDA-MB-231 cells.

(D)Immunofluorescence staining of N-cadherin,Snail, Vimentin and E-cadherin in MDA-MB-231 cells after transfection with NC siRNA or AnxA1 siRNA.(E)Western blot analysis of protein expression of transfection with AnxA1 shRNA and/ or treatment with UA.All Data represent the mean \pm SD in the three independent experiments. ${ }^{*} P<0.05,{ }^{*} \mathrm{P}<0.01$. 

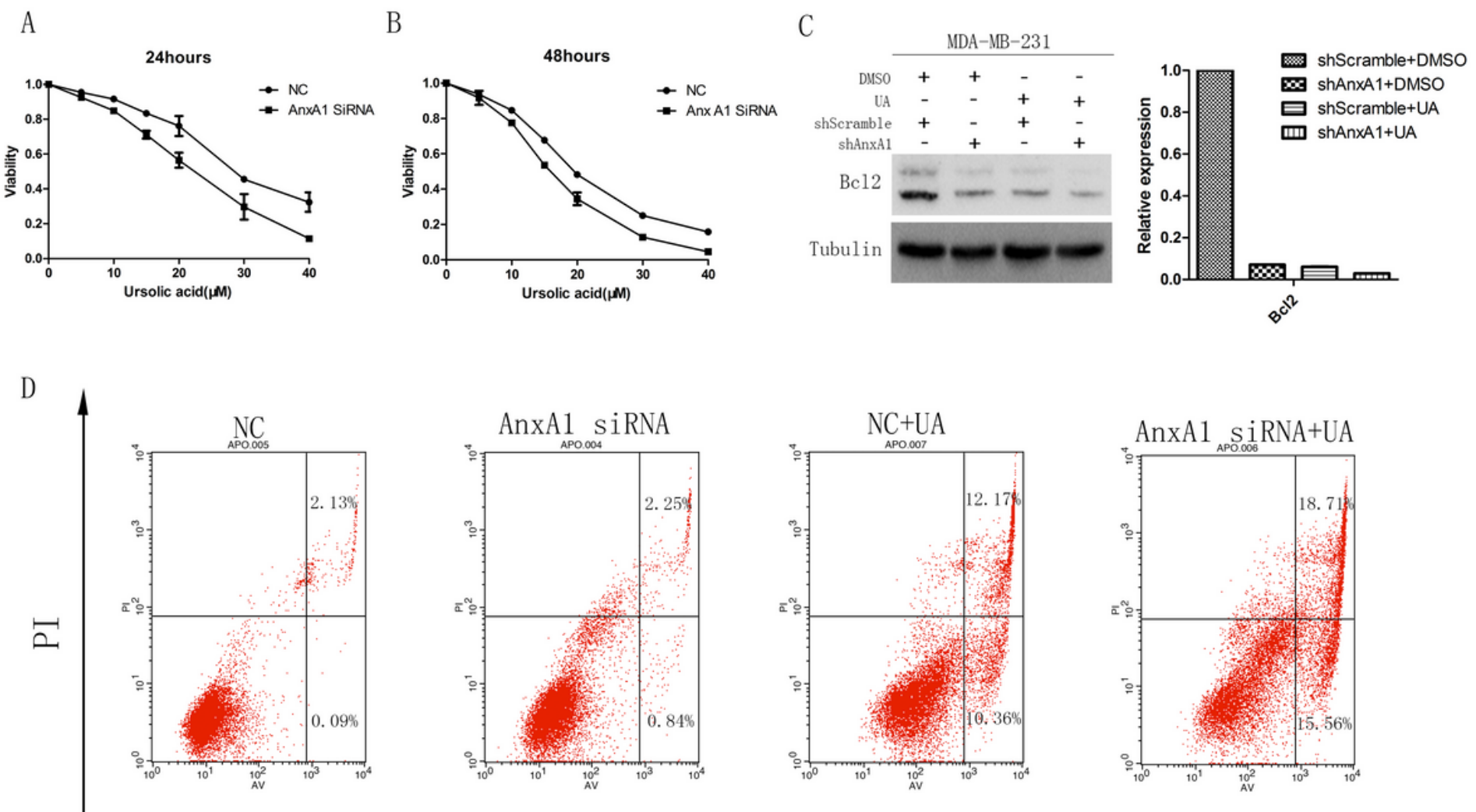

$\mathrm{AV}$

Figure 5

UA treatment targets AnxA1 to inhibit proliferation and accelerate apoptosis in MDA-MB-231 cells. (A, B) Cell viability of MDA-MB-231 following AnxA1 knockdown and UA treatment at various concentrations ( 0 , $5,10,15,20,30$ and $40 \mu \mathrm{M}$ ) for 24 and $48 \mathrm{~h}$. (C) Western blot analysis of MDA-MB-231 cell Bcl-2 expression of NC siRNA or AnxA1 siRNA group after UA treatment. (D)Flow cytometry analysis of transfection with AnxA1 shRNA and/ or treatment with UA.All Data represent the mean \pm SD in the three independent experiments. ${ }^{*} \mathrm{P}<0.05,{ }^{*} \mathrm{P}<0.01$. 
A

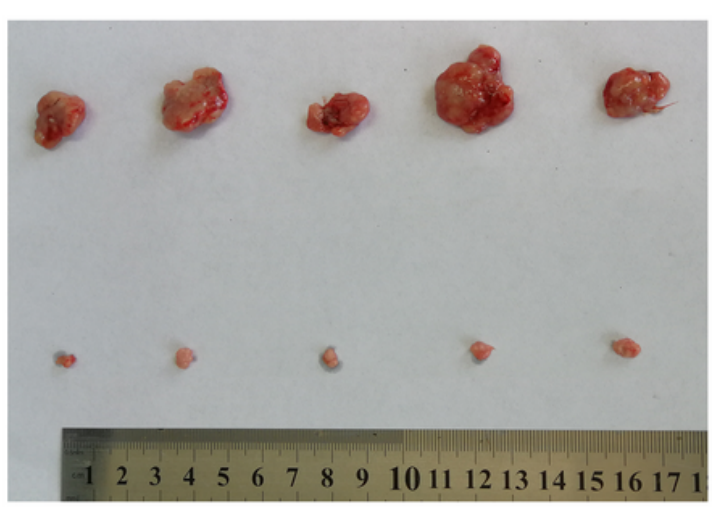

B

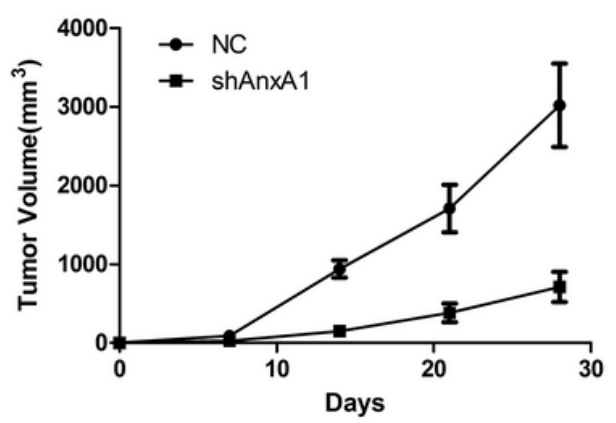

$\mathrm{C}$

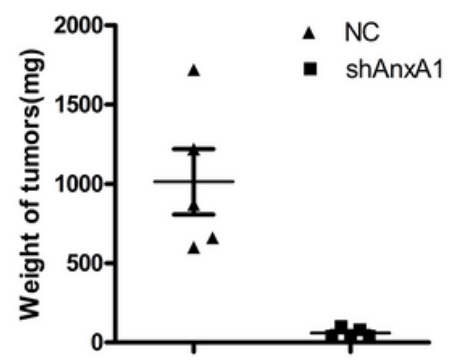

D AnxA1

Oct 4

$\mathrm{Bc} 12$

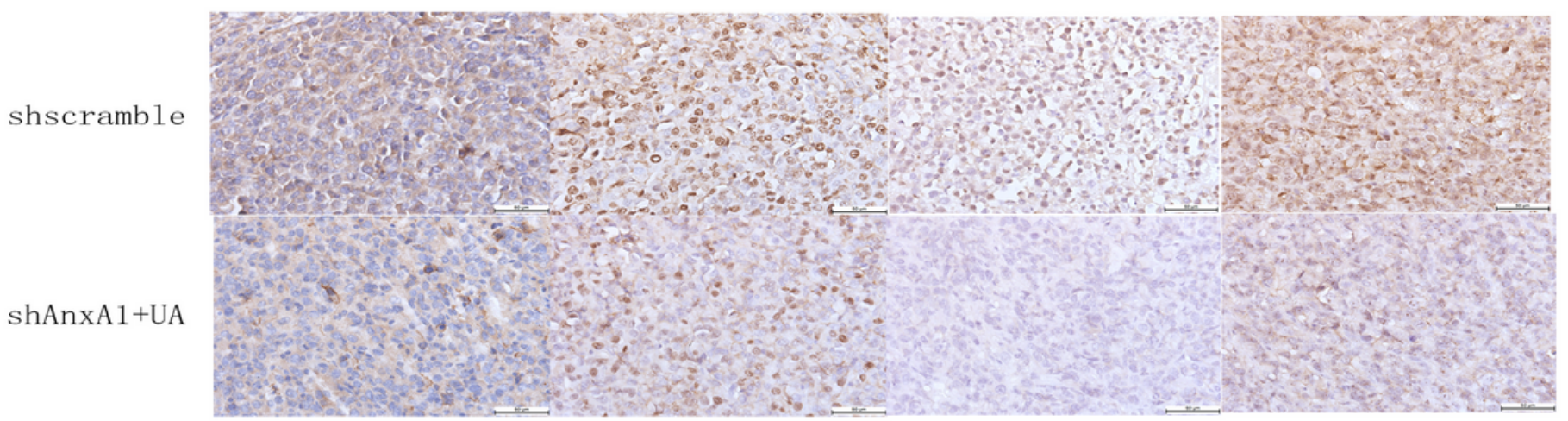

\section{Figure 6}

The combination of AnxA1 knockdown and UA treatment inhibits tumorigenicity . (A)Tumors were harvested from BALB/c nude mice at day 28 and imaged (B) Tumor xenografts volumes were detected every 7 days after injection. (C)Tumors weight were measured at 28 days. (D)Immunohistochemical detection of AnxA1, Ki67, Oct4, Bcl2 in tumor xenografts. All values present the mean $\pm S D,{ }^{*}<<0.05$, ${ }^{\star \star P}<$ 0.01 . 
A

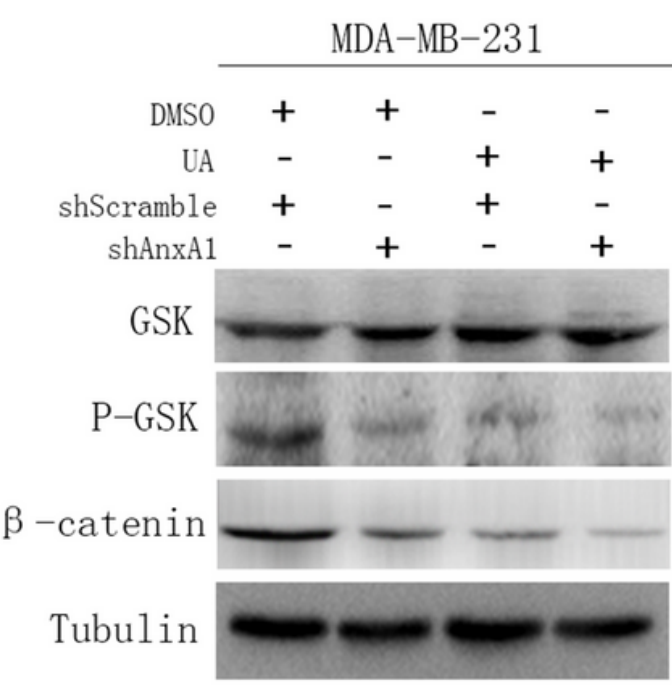

B
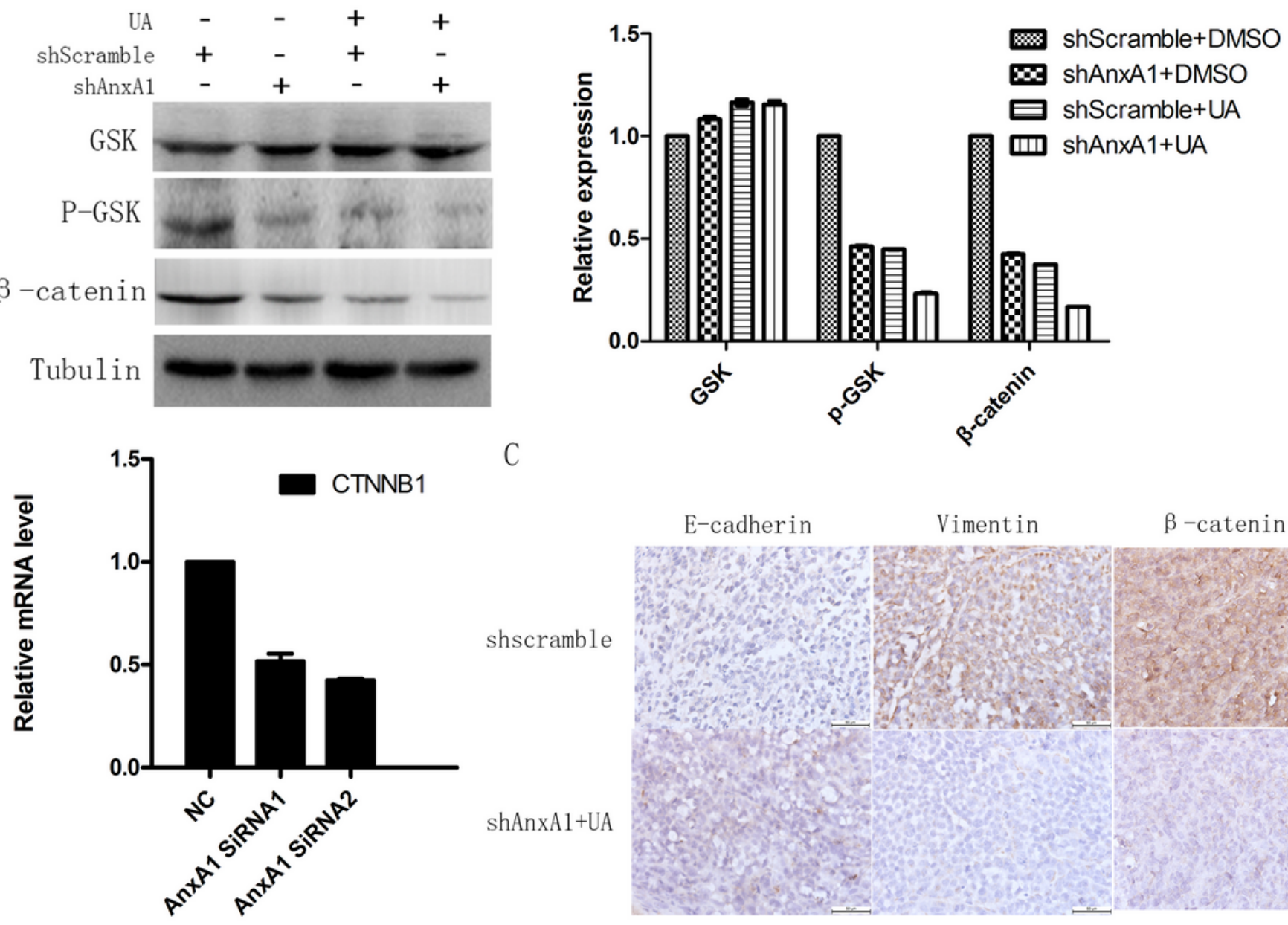

C

E-cadherin

Vimentin

$\beta$-catenin

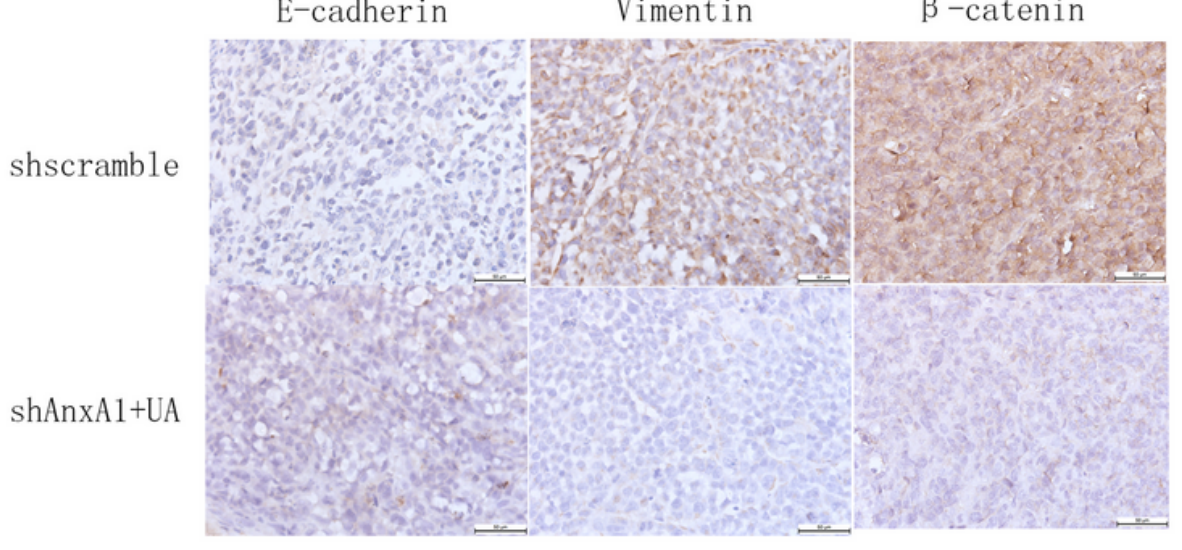

Figure 7

The combination effect of UA and AnxA1 on wnt/ $\beta$-catenin pathway in MDA-MB-231 cells. (A) The expression of GSK, p-GSK and $\beta$-catenin after transfection with AnxA1 shRNA and/or treatment with UA in MDA-MB- 231 cells by Western blot Assay. (B)Real-time quantitative PCR analysis of expression of $\beta$ catenin when knockdown of AnxA1 in MDA-MB-231 cells. (C) Immunohistochemical detection of Ecadherin, Vimentin and $\beta$-catenin in xenografts. All Data represent the mean $\pm S D$ in the three independent experiments. ${ }^{*} \mathrm{P}<0.05,{ }^{\star *} \mathrm{P}<0.01$. 